\title{
LIGHTWEIGHT CONCRETE MADE WITH WASTE EXPANDED POLYPROPYLENE-BASED AGGREGATE AND SYNTHETIC COAGULATED AMORPHOUS SILICA
}

\author{
MARTINA ZÁLESKÁ*, MILENA PAVLÍKOVÁ*, "ONDŘEJ JANKOVSKÝ**, \\ JAROSLAV POKORNÝ*, ZBYŠEK PAVLÍK* \\ * Department of Materials Engineering and Chemistry, Faculty of Civil Engineering, Czech Technical University in Prague, \\ Thákurova 7, 16629 Prague 6, Czech Republic \\ ** Department of Inorganic Chemistry, Faculty of Chemical Technology, University of Chemistry and Technology, \\ Technická 5, 16628 Prague 6, Czech Republic \\ \#E-mail: Ondrej.Jankovsky@vscht.cz
}

Submitted December 13, 2017; accepted March 2, 2018

\begin{abstract}
Keywords: Waste expanded polypropylene, Recycled plastic aggregate, Eco-Efficient lightweight concrete, Functional properties, Energy saving

Recycled plastic aggregate can be used as an alternative material to produce lightweight concrete with low environmental impact. Polypropylene is one of the least recycled post-consumer plastics. In the present study we focused at waste expanded polypropylene (EPP) aggregate that is used for partial replacement of natural aggregate to produce lightweight cementbased composites. Coagulated silica was used as admixture for improvement of dispersion of EPP particles in the cementbased matrix. At first, natural and EPP aggregates were examined. Coagulated silica was characterized by SEM, EDS, XRF, particles size distribution and pozzolanic activity. Analysis of the microstructure of lightweight concrete was performed using an optical microscope, SEM imaging and EDS. For the developed lightweight concrete, basic physical, mechanical and hygric properties were examined. Specific attention was paid to thermal properties. The results show, using of plastic waste aggregate led to a sufficient mechanical resistance, whereas the thermal insulation performance of the developed concrete was markedly improved. Composite with incorporated PP waste aggregates was found to be prospective material for nonstructural applications in building industry, which allows the development of buildings with optimum energy performance as well as reduce the growing environmental impact of waste polymers and saving the natural aggregates.
\end{abstract}

\section{INTRODUCTION}

Plastics have become an essential part of our modern lifestyle, and the global plastics production has increased immensely during the past 50 years. Plastics meet the needs of a variety range of products due to their favourable properties such as low density, high strengthto-weight ratio, high durability, ease of design and manufacture, and low cost [1]. Worldwide production of plastics in 2015 was approximately 322 Mt, with European production $58 \mathrm{Mt}$. In European plastics demand by polymer type in 2015 is in the first place polypropylene with $19.1 \%$, followed by low-density polyethylene (PE-LD) with $17.3 \%$ [2]. Most types of plastics are not biodegradable and are chemically unreactive in the natural environment; hence such polymer product persists for decades, even for centuries, causing long-term environmental pollution [1]. The continued growth of worldwide plastic consumption in recent years and consequently increased quantity of plastic-related waste requires new forms of recycling, avoiding landfill disposal [3]. Plastic recycling rate in Europe in recent years have increased to almost $30 \%$, whereas landfilling and energy recovery still constitutes a large part of plastic waste treatment [2]. However, the recycle ratio for PP is very low. For example in United States in 2012 was only $0.6 \%$, which makes it one of the least recycled postconsumer plastics [1].

The building industry consumes huge amount of natural resources and also is one of the largest consumers of energy in many countries. This energy can be categorized as embodied energy (energy needed by process associated with the completion of a building, includes acquisition of natural resources, manufacturing of material, transporting, etc.) and operational energy (air conditioning, heating, lighting etc.) [4]. In recent years, one can see further increase in energy usage with worldwide economic development. The close interrelationships between building materials and energy should therefore be well addressed and investigated [5]. For the improvement of energy performance of buildings, the use of materials with effective thermal insulation properties should be taken into consideration [6].

Reuse of waste and recycled plastic materials in concrete as an environmental friendly construction material has drawn attention of researchers in recent times, 
and a large number of studies reporting the behavior of concrete containing waste and recycled plastic materials have been published [7]. The use of recycled plastic waste as partial replacement of the natural aggregate in the concrete production contributes to environmental benefits in several ways. On the one hand, it avoids the need to obtain, produce and exploit natural materials (with the correspondent environmental impact that it implies) while it gives a solution to treat waste material [8]. Moreover, with regard to the operational energy of buildings, the obtained lightweight concrete with plastic aggregate is characterized by enhanced thermal insulation performance.

Most of the existing studies on plastic aggregates were concerned with the use of polyethylene terephthalate (PET), high density polyethylene (HDPE) and expanded polystyrene (EPS). On the other hand, papers related with polypropylene (PP) are relatively few. Ozbakkaloglu and $\mathrm{Gu}$ [1] studied short-term mechanical properties of concrete with recycled polypropylene coarse aggregates and stated that recycled plastic aggregate concrete brings lower mechanical resistance compared to reference concrete mixture. In other studies, PP was used in mixture with other types of plastics or with another waste as fly ash or wood $[3,5,9,10,11]$. To date no study has been reported on the use of waste expanded polypropylene (EPP) as aggregate. In general, from literature it follows that all types of plastic aggregate can reduce the cost and significantly improve unit weight and the thermal and acoustic performance of developed concretes $[12,13,14]$. However, many papers reported worsening of mechanical properties of concrete containing plastic waste aggregate $[7,13,15]$.

Therefore, the presented study is focused on the use of waste expanded polypropylene coming from the aircraft model production as partial replacement of natural aggregate for the development of lightweight concrete. Main objective of this research is assessment of the lightweight concrete incorporating expanded polypropylene aggregates in terms of its physical, mechanical and hygric properties and in particular of preferable thermal attributes and optimum energy performance in building construction.

\section{EXPERIMENTAL}

\section{Materials and sample preparation}

Expanded polypropylene (EPP) used in this research was obtained as shredded waste from aircraft model production. The main objective was to produce a light-weight concrete containing as much waste plastic aggregate as possible, to get material with improved thermal properties, which nevertheless still meets the requirements for workability and strength. For preparation of lightweight concrete was used Portland cement CEM I 42.5 R (Czech-Moravian cement Ltd., HeidelbergCement
Group, Mokrá plant), silica sand (Filtrační písky, Ltd., affiliate Chlum u Doks), synthetic coagulated amorphous $\mathrm{SiO}_{2}$ (Silica VP4, AV EKO-COLOR, Ltd.), potable water and EPP aggregate, which replaced $60 \%$ by volume of silica sand. The amount of EPP used was selected on the basis of preliminary tests. Reference mixture without EPP was prepared as well. To achieve good workability, Dynamon SX (Mapei Ltd.) as superplasticizer was used. The silica sand as natural aggregate was mixed from three sand fractions in weight ratio $1: 1: 1$. The water/cement ratio was 0.5 for the both examined mixtures. Because ultra-lightweight aggregate tends to float and can result in a poor mix distribution and segregation [16], silica VP4 was added to the mixture. Silica VP4 acted in this case as an admixture for improvement of dispersion of EPP particles in the cement matrix and as a pozzolan [17, $18,19]$. The composition of tested concretes is given in Table 1.

Table 1. Composition of examined concrete mixtures.

\begin{tabular}{lccccccc}
\hline & $\begin{array}{c}\text { CEM } \\
(\mathrm{g})\end{array}$ & $\begin{array}{c}\text { VP4 } \\
(\mathrm{g})\end{array}$ & $\begin{array}{c}\text { Sand } \\
(\mathrm{ml})\end{array}$ & $\begin{array}{c}\text { EPP } \\
(\mathrm{ml})\end{array}$ & $\begin{array}{c}\text { Water } \\
(\mathrm{g})\end{array}$ & $\begin{array}{c}\text { Dynamon } \\
(\mathrm{g})\end{array}$ & w/c \\
\hline $\mathrm{R}$ & 1387.5 & 112.5 & 3300 & 0 & 750 & 30 & 0.5 \\
$\mathrm{EPP}$ & 1387.5 & 112.5 & 1300 & 2000 & 750 & 30 & 0.5 \\
\hline
\end{tabular}

The casted prismatic samples having dimensions of $40 \times 40 \times 160 \mathrm{~mm}$, cubic samples with side dimension of $70 \mathrm{~mm}$, and flat cylinder samples with diameter of 100 $\mathrm{mm}$ and thickness of about $30 \mathrm{~mm}$ were left for 1 day at laboratory conditions, and then they were unmoulded and cured for 28 days (R28, EPP28) or 90 days (R90, EPP90) in water having temperature of $23 \pm 2{ }^{\circ} \mathrm{C}$. The example of the tested samples is given in Figure 1.

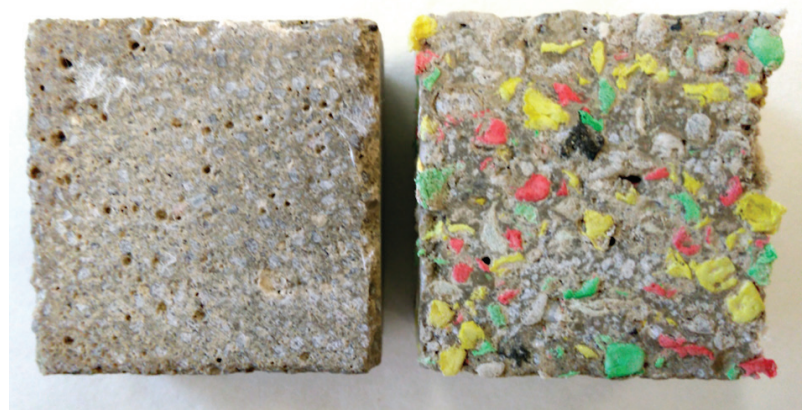

Figure 1. Tested reference (left) and EPP (right) concrete samples.

\section{Aggregate and silica VP4 characterization}

Natural and waste plastic aggregates (Figure 2) were characterized in terms of particle size, matrix density and in particular of the thermal transport and storage properties, which were determined in dependence on powder density and material compacting. 


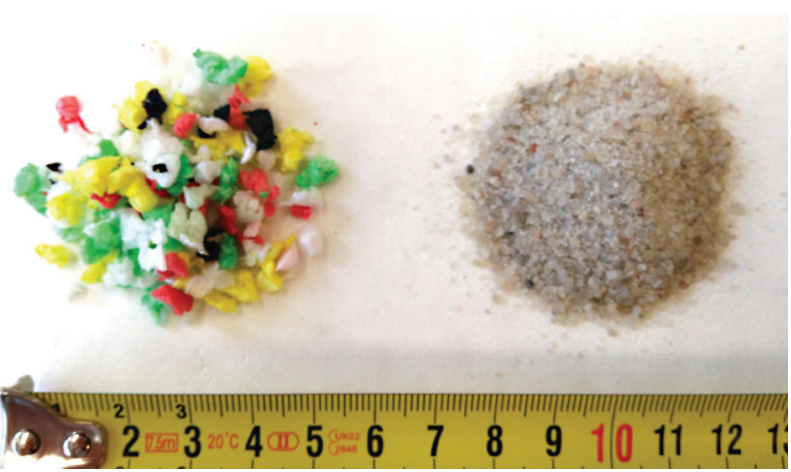

Figure 2. EPP (left) and natural aggregates.

For both EPP particles and mixed silica sand, measurements of grain-size curves were done. The grainsize analysis was realized using standard sieve method with sieves of following mesh dimensions: $0.063 ; 0.125$; $0.25 ; 0.5 ; 1.0 ; 2.0 ; 4.0 ; 8.0 ; 16.0 ; 31.5$ and $63.0 \mathrm{~mm}$. Specific density of EPP aggregate was measured using automatic helium pycnometer Pycnomatic ATC (Thermo Scientific) with fully integrated temperature control with stability of $0.02^{\circ} \mathrm{Cand}$ real multi volume density analyser. For thermal performance assessment of both natural and EPP aggregates, their powder density and thermal properties namely thermal conductivity $\lambda\left(\mathrm{W} \cdot \mathrm{m}^{-1} \cdot \mathrm{K}^{-1}\right)$, volumetric heat capacity $C_{v}\left(\mathrm{~J} \cdot \mathrm{m}^{-3} \cdot \mathrm{K}^{-1}\right)$ and thermal diffusivity $a\left(\mathrm{~m}^{2} \cdot \mathrm{s}^{-1}\right)$ were measured in dependence on compaction time. During the test, the particular aggregate was put into graduated cylinder and compacted using the vibration exciter. From the known mass of the sample in cylinder and its volume, the powder density was determined. Thermal parameters of aggregates were measured using the commercially produced device ISOMET 2114 (Applied Precision, Ltd.) working on a transient impulse method principle [20]. For the measurement of both natural and EPP aggregates, needle probe impressed into graduated cylinder with compacted aggregates was applied. The measurement accuracy was $5 \%$ of reading $+0.001 \mathrm{~W} \cdot \mathrm{m}^{-1} \cdot \mathrm{K}^{-1}$ for the thermal conductivity in the range $0.015-0.70 \mathrm{~W} \cdot \mathrm{m}^{-1} \cdot \mathrm{K}^{-1}$ and $10 \%$ of reading for the thermal conductivity ranging from $0.70 \mathrm{~W} \cdot \mathrm{m}^{-1} \cdot \mathrm{K}^{-1}$ to $6.0 \mathrm{~W} \cdot \mathrm{m}^{-1} \cdot \mathrm{K}^{-1}$. The accuracy of the volumetric heat capacity was $15 \%$ of reading $+1 \times 10^{3} \mathrm{~J} \cdot \mathrm{m}^{-3} \cdot \mathrm{K}^{-1}$. Microstructure of EPP particles was study using Dino-Lite digital optical microscope with resolution of $5 \mathrm{Mpx}$.

Silica VP4 was investigated by X-Ray fluorescence analysis (XRF) using an Axios sequential WD-XRF spectrometer (PANanalytical) equipped with an Rh anode end-window X-ray tube fitted with a $50 \mu \mathrm{m}$ beryllium window. The morphology was study using scanning electron microscopy (SEM) with a FEG electron source (Tescan Lyra dual beam microscope). Energy dispersive spectroscopy (EDS) was performed for elemental composition and mapping using analyzer $\mathrm{X}-\mathrm{Max}^{\mathrm{N}}$ with a $20 \mathrm{~mm}^{2}$ SDD detector (Oxford instruments) and AZtecEnergy software. Particle size distribution was determined by an Analysette 22 Micro Tec plus (Fritsch) device working on a laser diffraction principle. This device uses red laser for measurement of bigger particles and green laser for finer particles, whereas the laser analyser allows measurement of grain size in the range of $0.08-2000 \mu \mathrm{m}$. Matrix density was accessed by helium pycnometry as described above and the specific surface was investigated using Blain apparatus according to the standard EN 196-6 (1989) [21]. The powder density was evaluated as well. The determination of pozzolanic activity was performed using modified Chapelle test $[22,23]$, which is specified in French norm NF P 18513 (2009) [24]. The principle of the method is based on the reaction of $1 \mathrm{~g}$ of tested powder material with $2 \mathrm{~g}$ $\mathrm{CaO}$ in the water at $80^{\circ} \mathrm{C}$ during 24 hours. The result was expressed in $\mathrm{mg} \mathrm{Ca}(\mathrm{OH})_{2}$ fixed by the $1 \mathrm{~g}$ of the sample and give the straight information about pozzolanic activity [25]. The minimum amount of $\mathrm{Ca}(\mathrm{OH})_{2}$ fixed by a material should be $650 \mathrm{mg} \cdot \mathrm{g}^{-1}$ to consider it as pozzolanic [26, 27].

\section{Application of EPP aggregates in light-weight concrete}

In order to assess the effect of plastic particles on the properties of fresh concrete, flow table test was performed according to the EN 12350-5 (2009) [28]. For the hardened concrete samples, which were cured in 28 resp. 90 days in water, basic physical, mechanical, hygric and thermal properties were investigated.

The matrix density was measured by helium pycnometry (see above). The bulk density was accessed using the measurement of sample sizes and dry mass of the sample according to EN 12390-7 (2009) [29]. Before measurement, samples were dried in a vacuum drier at $60^{\circ} \mathrm{C}$. The total porosity was than obtained on the basis of the bulk density and matrix density measurement. The relative expanded combined uncertainty of applied measuring method was $5 \%$.

Mechanical resistivity of tested materials was characterized by compressive strength, flexural strength and Young's modulus. Both strength tests were carried out according to the standard EN 196-1 (2016) [30] and their relative expanded uncertainty was $1.4 \%$. The flexural strength was determined on $40 \times 40 \times 160 \mathrm{~mm}$ prismatic samples. The compressive strength was measured on the broken halves of samples from the flexural strength test, whereas loading area was $40 \times 40 \mathrm{~mm}$. The Young's modulus of elasticity was determined on a dynamic principle using the pulse ultrasonic method. The measurement was done on $40 \times 40 \times 160 \mathrm{~mm}$ prismatic samples in a longitudinal direction using device DIO 562 (Starmans Electronic) working on the frequency of $50 \mathrm{KHz}$. Before the ultrasonic measurement, the samples were dried in a vacuum drier at $60^{\circ} \mathrm{C}$. The relative expanded uncertainty of the dynamic Young's modulus measurement was $2 \%$ [31]. 
The microstructure and morphology of concrete samples was studied using an optical microscopy and scanning electron microscopy (SEM). Energy dispersive spectroscopy (EDS) was used for elemental composition and mapping (all used methods have been described above).

In order to assess the effect of plastic waste aggregate on improvement of heat transport and storage properties of the studied light-weight concrete, thermal conductivity $\lambda\left(\mathrm{W} \cdot \mathrm{m}^{-1} \cdot \mathrm{K}^{-1}\right)$, volumetric heat capacity $C_{v}\left(\mathrm{~J} \cdot \mathrm{m}^{-3} \cdot \mathrm{K}^{-1}\right)$ and thermal diffusivity $a\left(\mathrm{~m}^{2} \cdot \mathrm{s}^{-1}\right)$ were measured. Since the thermal properties were of the particular importance for lightweight concrete use, they were measured using commercially produced device ISOMET 2114 (see above) in dependence on moisture content, from the dry state to fully water saturated state. Composite samples in form of cubes with side dimension of $70 \mathrm{~mm}$ were measured using circular surface probe. Details on the measurement accuracy are given above in section about aggregate characterization.

For characterization liquid water transport in studied materials, free water intake experiment for determination of water absorption coefficient $A\left(\mathrm{~kg} \cdot \mathrm{m}^{2} \cdot \mathrm{s}^{-1 / 2}\right)$, water sorptivity $S\left(\mathrm{~m} \cdot \mathrm{s}^{-1 / 2}\right)$ and the apparent moisture diffusivity $\kappa_{a p p}\left(\mathrm{~m}^{2} \cdot \mathrm{s}\right)$ was conducted. Dried cubic samples were water and vapour-proof insulated by epoxy resin on all lateral sides. Than they were exposed by their $70 \times 70 \mathrm{~mm}$ face to the distilled water and the weight change of the samples in time was monitored and registered. The water absorption coefficient $A$ is than defined as the slope of the initial stage of the cumulative mass of water vs. square root of time. The water sorptivity $S$ was determined using the Equation 1

$$
A=S \times \rho_{w},
$$

where $\rho_{w}$ is the density of water $\left(\mathrm{kg} \cdot \mathrm{m}^{-3}\right) . \kappa_{a p p}$ was calculated according to the Equation 2 [32]

$$
\kappa_{\text {app }} \approx\left(\frac{A}{w_{\text {sat }}-w_{0}}\right)^{2}
$$

where $w_{\text {sat }}$ is the saturated moisture content $\left(\mathrm{kg} \cdot \mathrm{m}^{-3}\right)$ and $w_{0}$ the initial moisture content $\left(\mathrm{kg} \cdot \mathrm{m}^{-3}\right)$. The expanded combined uncertainty in the determination of the water absorption coefficient was $2.3 \%$ and of the apparent moisture diffusivity $3.5 \%$.

Determination of water vapour transport parameters of developed concrete was done using the cup method in accordance with the standard EN ISO 12572 (2001) [33]. The cup method was based on one-dimensional water vapour diffusion, where the gradient of water vapour pressure in the air above and under specific surface of sample caused the water vapour flow through the sample. Test was performed in steady state under isothermal conditions (temperature of $23 \pm 1^{\circ} \mathrm{C}$, relative humidity of $50 \pm 5 \%$ ), whereas both the dry-cup and wet-cup arrangements of the cup method were employed for the measurement. The equilibrium relative humidity in a cup was $97.8 \%$ above the saturated solution of $\mathrm{K}_{2} \mathrm{SO}_{4}$ resp. $2 \%$ above the desiccant. For the measurement, flat cylindrical samples with diameter of $100 \mathrm{~mm}$ and thickness of about $30 \mathrm{~mm}$ were used. Based on the periodic weighing of the cups with sealed samples, the water vapour diffusion coefficient $D\left(\mathrm{~m}^{2} \cdot \mathrm{s}^{-1}\right)$ and the water vapour diffusion resistance factor $\mu(-)$ were calculated.

For characterization of the prepared materials in terms of the water vapour adsorption capacity, the sorption isotherms expressing the dependence of the moisture content of the sample on the relative humidity of the surrounding environment were determined [34]. Fragments of samples from mechanical tests were used for measurement, whereas the initial stage was dry material. Test was conducted in a climatic chamber with controlled temperature of $23 \pm 1{ }^{\circ} \mathrm{C}$. Samples were periodically weighed and the relative humidity in the climatic chamber was stepwise increased after the stabilization of sample weight at specific relative humidity environment. For each set equilibrium relative humidity, the corresponding moisture content $u\left(\mathrm{~kg}^{\mathrm{kg}} \mathrm{kg}^{-1}\right)$ was accessed.

\section{RESULTS AND DISCUSSION}

Results of grain-size analysis of both natural and EPP aggregates are shown in Figure 3. It can be observed that $100 \%$ of EPP particles were smaller than $8 \mathrm{~mm}$, what is favourable for their use as a silica sand replacement.

The specific density of EPP achieved value of $105 \mathrm{~kg} \cdot \mathrm{m}^{-3}$, which ranks EPP aggregate among artificial ultra-lightweight (density of less than $300 \mathrm{~kg} \cdot \mathrm{m}^{-3}$ ) nonabsorbent aggregates as classified by Babu and Babu [16]. Thermophysical parameters of EPP aggregate as well as natural aggregate and their corresponding powder density are presented in Table 2 . We can see that the EPP aggregate had significantly lower heat

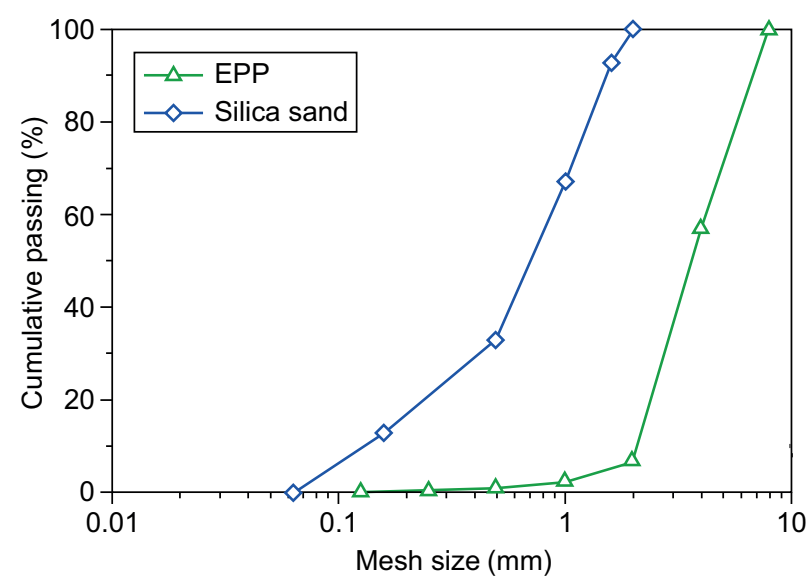

Figure 3. Grain-size curves of used mixed silica sand and EPP waste. Mesh size is in logarithmic scale. 
transport parameters than silica sand typically used in concrete production. On the other hand, volumetric heat capacity of silica sand was markedly higher compared to EPP. This was due to its high density and mineral origin. With increasing time of compaction, the thermal conductivity and volumetric heat capacity increased due to the elimination of air gaps between the particles. This aggregates behaviour can be anticipated during preparation of lightweight concrete with incorporated EPP aggregate.

Morphology obtained from optical microscopic investigation of EPP aggregate is shown in Figure 4. One can see highly porous character of close EPP bead what is conductive with its low weight, high strength-toweight ratio, thermal and sound insulation properties.

Table 3 gives chemical composition and properties of used coagulated silica VP4. Coagulated silica exhibited high specific surface and high content of silica what led to its high pozzolanic activity that is promising in terms of its reactivity in cement-based mixtures.

Figures 5, 6 show the particle size distribution curves of coagulated silica VP4 in the comparison with
Portland cement (CEM I 42.5 R). We can see that particles of silica VP4 were coarser compared to data obtained for Portland cement. Nevertheless, Blain fineness of silica VP4 was much higher compared to the value measured for cement used.

Table 3. Chemical composition (XRF) and properties of coagulated silica VP4.

\begin{tabular}{lr}
\hline Substance & (mass \%) \\
\hline $\mathrm{SiO}_{2}$ & 98.93 \\
$\mathrm{Al}_{2} \mathrm{O}_{3}$ & 0.11 \\
$\mathrm{Na}_{2} \mathrm{O}$ & 0.84 \\
$\mathrm{C}$ and other elements & 0.13 \\
\hline Matrix density $\left(\mathrm{kg} \cdot \mathrm{m}^{-3}\right)$ & 2348 \\
\hline Powder density $\left(\mathrm{kg} \cdot \mathrm{m}^{-3}\right)$ & 186 \\
\hline Blain specific surface $\left(\mathrm{m}^{2} \cdot \mathrm{kg}^{-1}\right)$ & 5210 \\
\hline Pozzolana activity $\left(\mathrm{mg} \mathrm{Ca}(\mathrm{OH})_{2}\right.$ fixed by $\left.1 \mathrm{~g}^{-1}\right)$ & 1530 \\
\hline
\end{tabular}

Table 2. Aggregate properties in dependence on the compaction time.

\begin{tabular}{|c|c|c|c|c|c|}
\hline $\begin{array}{l}\text { Aggregate } \\
\text { type }\end{array}$ & $\begin{array}{l}\text { Compaction time } \\
\text { (s) }\end{array}$ & $\begin{array}{l}\text { Powder density } \\
\qquad\left(\mathrm{g} \cdot \mathrm{cm}^{-3}\right)\end{array}$ & $\begin{array}{c}\lambda \\
\left(\mathrm{W} \cdot \mathrm{m}^{-1} \cdot \mathrm{K}^{-1}\right)\end{array}$ & $\begin{array}{c}C_{v} \\
\left(\times 10^{6} \mathrm{~J} \cdot \mathrm{m}^{-3} \cdot \mathrm{K}^{-1}\right)\end{array}$ & $\begin{array}{c}a \\
\left(\times 10^{-6} \mathrm{~m}^{2} \cdot \mathrm{s}^{-1}\right)\end{array}$ \\
\hline \multirow{5}{*}{ EPP } & 0 & 0.0189 & 0.042 & 0.049 & 0.96 \\
\hline & 10 & 0.0224 & 0.043 & 0.055 & 0.80 \\
\hline & 30 & 0.0233 & 0.044 & 0.058 & 0.75 \\
\hline & 60 & 0.0239 & 0.044 & 0.061 & 0.72 \\
\hline & 180 & 0.0243 & 0.047 & 0.062 & 0.69 \\
\hline \multirow{5}{*}{ Silica sand } & 0 & 1.657 & 0.410 & 1.569 & 0.261 \\
\hline & 10 & 1.910 & 0.562 & 1.681 & 0.334 \\
\hline & 20 & 1.916 & 0.575 & 1.683 & 0.342 \\
\hline & 30 & 1.922 & 0.576 & 1.684 & 0.341 \\
\hline & 60 & 1.927 & 0.577 & 1.689 & 0.341 \\
\hline
\end{tabular}

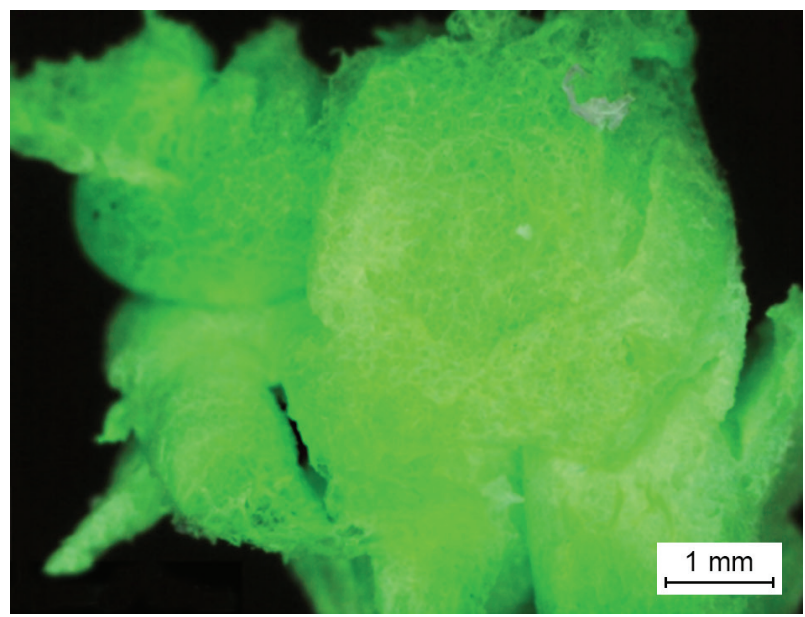

a)

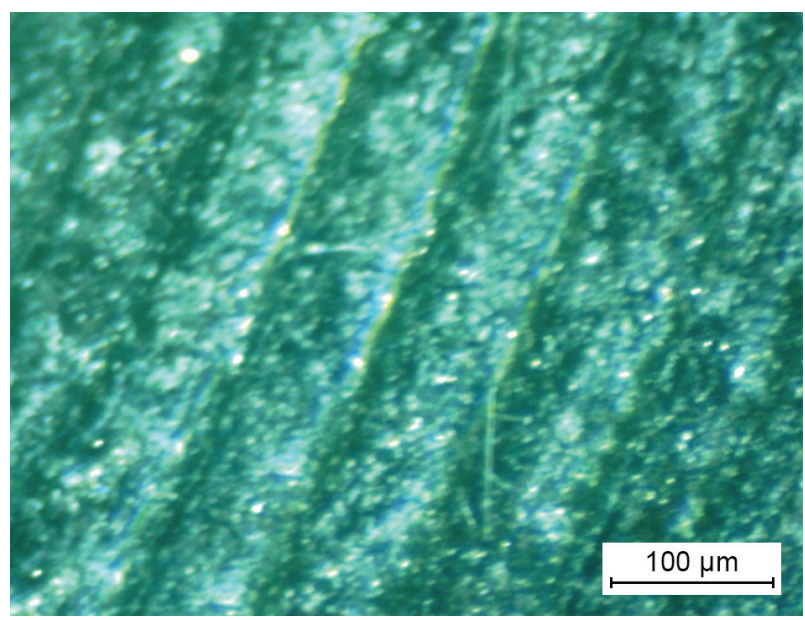

b)

Figure 4. EPP particle image obtained by optical microscopy. 


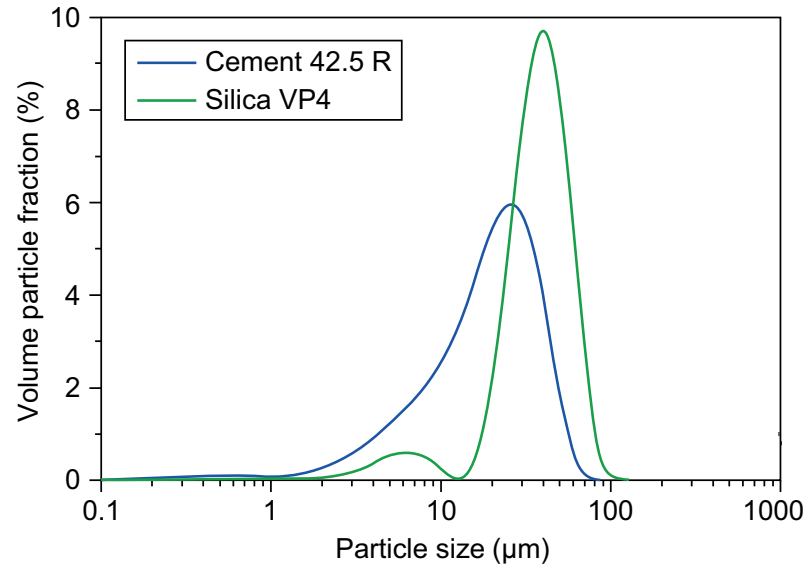

Figure 5. Particle size distribution - incremental curves.

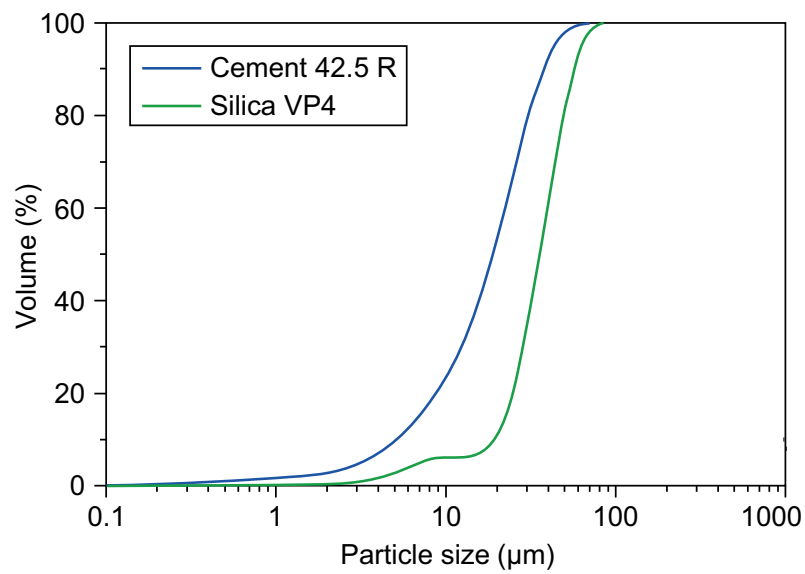

Figure 6. Particle size distribution - cumulative curves.

Figure 7 presents morphology of silica VP4 obtained by SEM and the elemental distribution maps analysed by energy dispersive spectroscopy. The EDS data clearly corresponds with results of chemical composition of coagulated silica and gives information on uniform distribution of $\mathrm{Si}$ and $\mathrm{O}$. On the other hand, $\mathrm{Na}$ seems to be more clustered that can suggest presence of carbonates.

The flow diameter was $150 \mathrm{~mm}$ for reference concrete mixture and $140 \mathrm{~mm}$ for mixture with EPP aggregate. Both reference and EPP mixtures were easily workable and compactable. The problems associated with the segregation and poor distribution of EPP particles in the mixture were solved by silica VP4 addition, since silica VP4 and the superplasticizer improved the cohesiveness of the fresh mixture.

Microscopic study of the developed concrete with EPP particles obtained by optical microscopy is given in Figure 8. We can see dense structure of the developed material and good incorporation of EPP particles into cement-based matrix.

The morphology of the developed EPP material analysed by SEM is shown in Figure 9. It can be observed that despite the scaly surface of the EPP particle, it adheres sufficiently to the cement-based matrix.

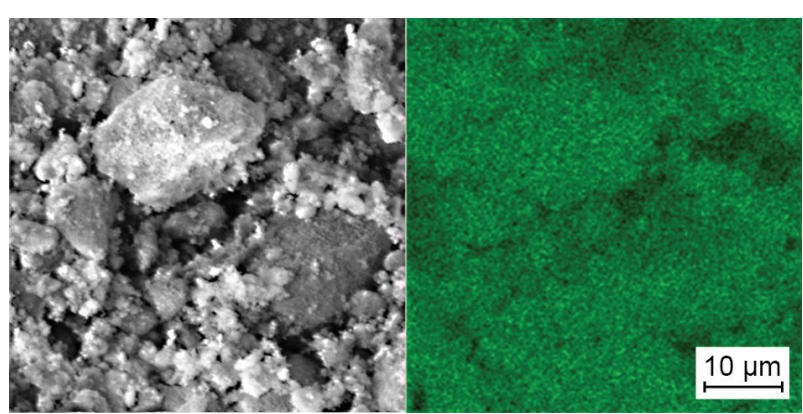

$\mathrm{Si} \mathrm{K} \alpha 1$

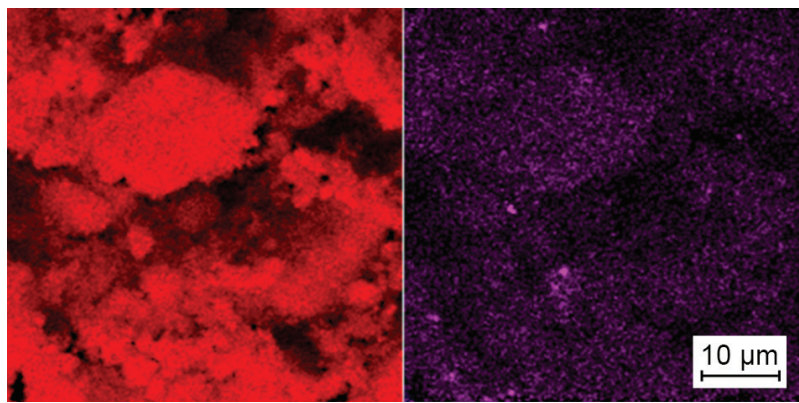

$\mathrm{O} \mathrm{K} \alpha 1$

$\mathrm{Na} \mathrm{K} \alpha 12$

Figure 7. The morphology of silica VP4 obtained by SEM and elemental maps of individual elements.

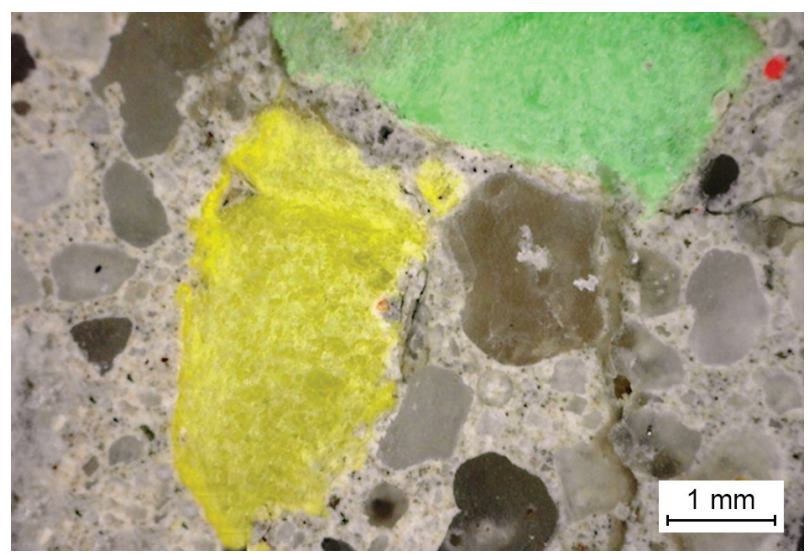

Figure 8. Image of lightweight concrete containing EPP particles obtained by optical microscopy.

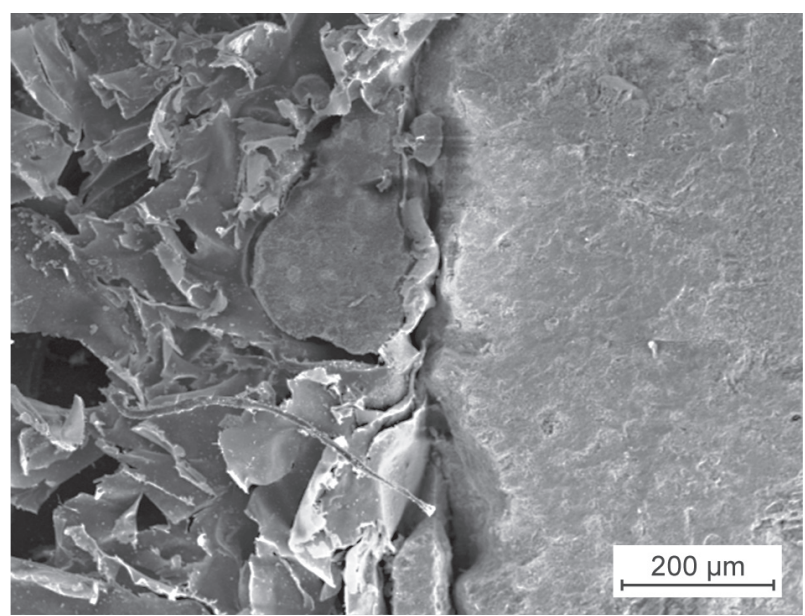

Figure 9. SEM image of concrete sample with EPP particles. 
In Figure 10 we can see SEM image of EPP particle in the cement-based matrix with corresponding overall elemental map and maps of selected individual elements. Carbon was mainly found in the central area containing polymer. From elemental maps of other elements, the presence of $\mathrm{SiO}_{2}$ (green colour in right top image) and calcium silicates and hydrates (red colour in right top image) was confirmed. This corresponds to the products of cement/silica hydration, nominally to $\mathrm{C}-\mathrm{H}$ (Portlandite) and C-S-H phases of different forms [35]. Moreover, the presence of alumina (violet colour in right top image) gives evidence of occurrence of $\mathrm{C}-\mathrm{A}-\mathrm{H}$ and $\mathrm{C}-\mathrm{S}-\mathrm{A}-\mathrm{H}$ phases.

Data on matrix density, bulk density and porosity of the developed concretes after 28 days resp. 90 days of water curing are presented in Table 4.
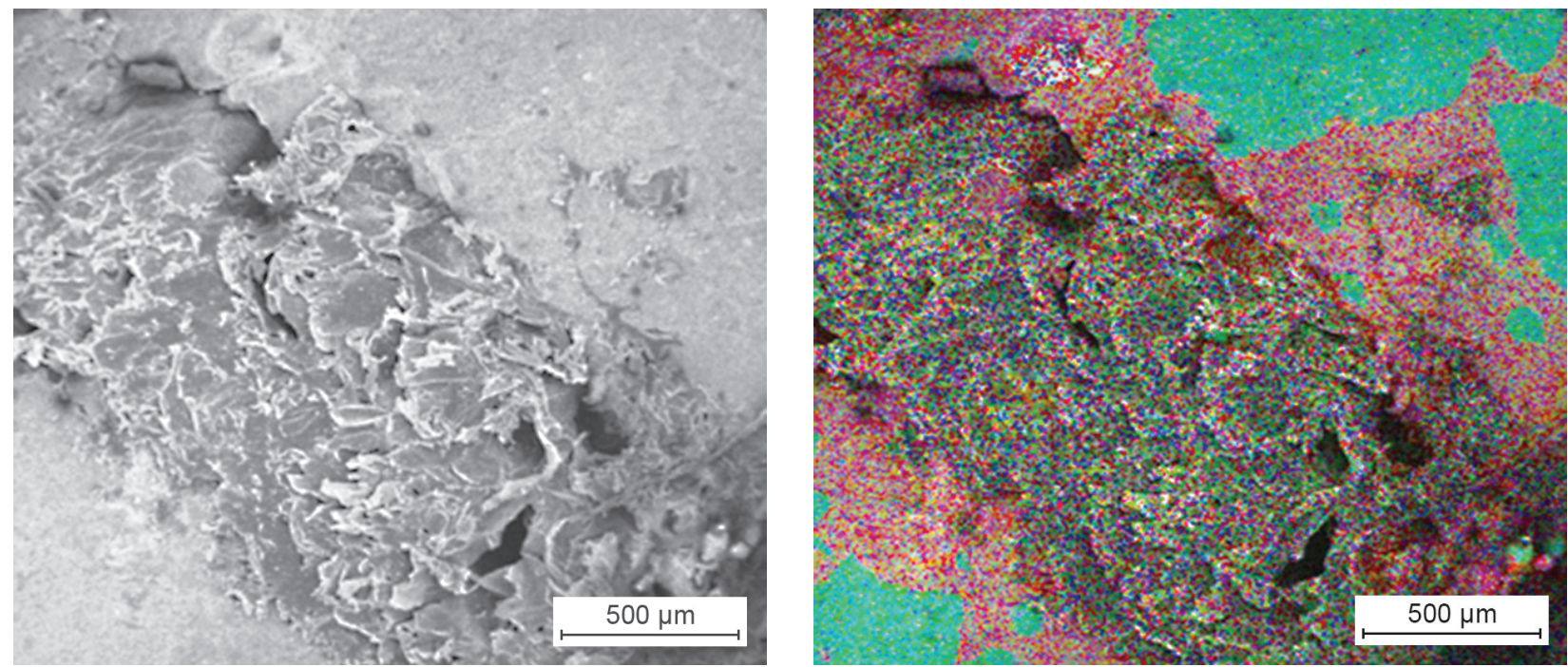

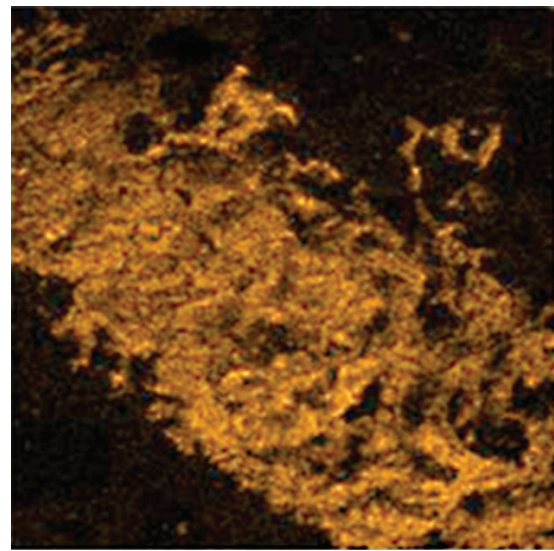

$\mathrm{C} K \alpha 12$

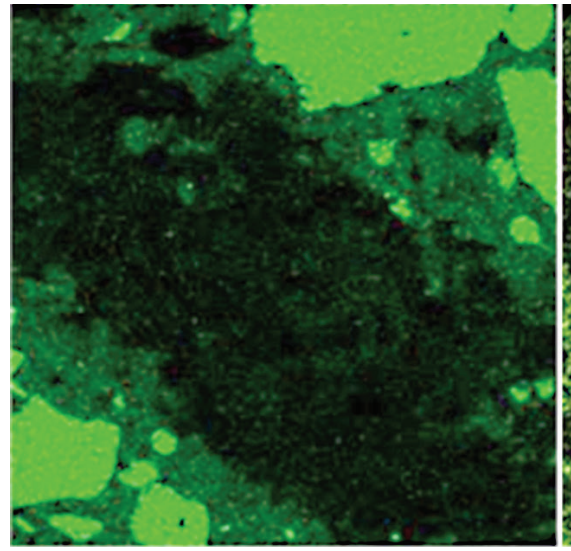

Si K $\alpha 1$

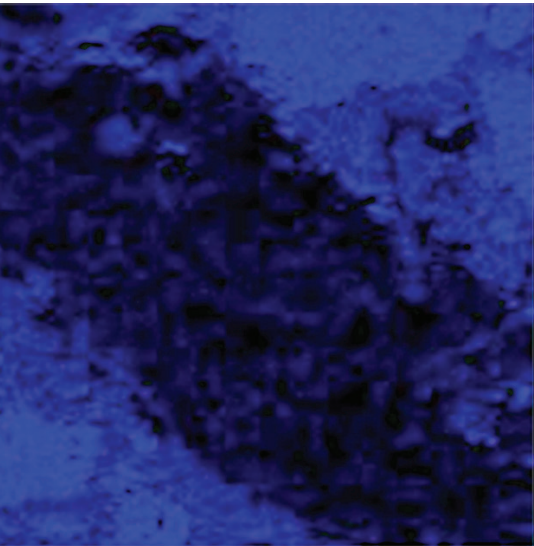

$\mathrm{O} \mathrm{K} \alpha 1$

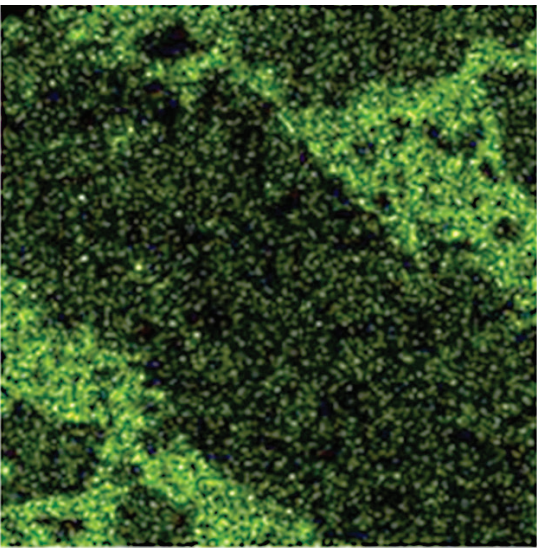

$\mathrm{K} \mathrm{K} \alpha 1$

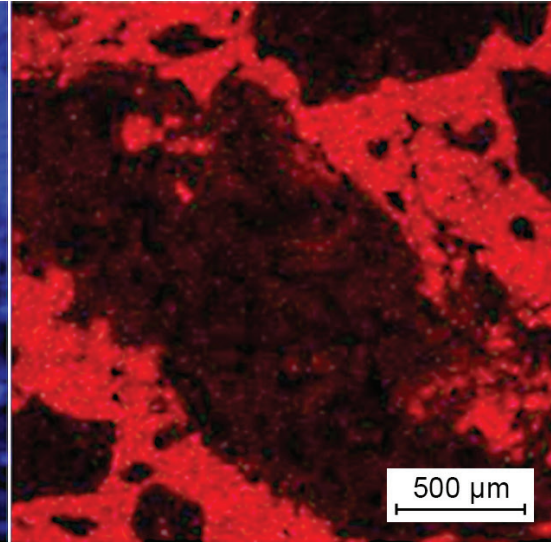

$\mathrm{Ca} \mathrm{K} \alpha 1$

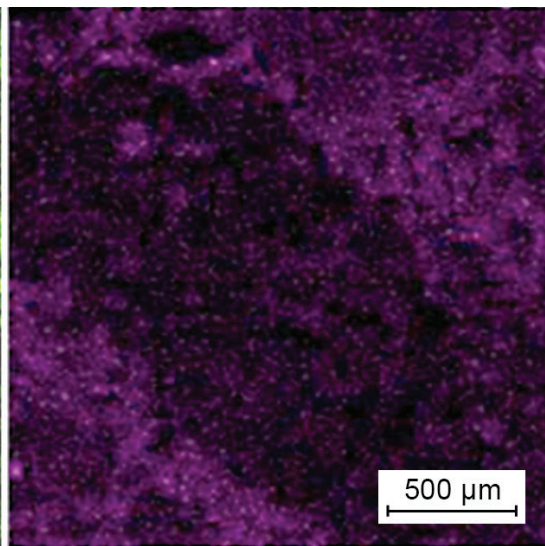

$\mathrm{Al} \mathrm{K} \alpha 1$

Figure 10. SEM images and elemental maps of lightweight concrete with EPP aggregates. 
Table 4. Basic physical properties of tested materials.

\begin{tabular}{lccc}
\hline Material & $\begin{array}{c}\text { Matrix density } \\
\left(\mathrm{kg} \cdot \mathrm{m}^{-3}\right)\end{array}$ & $\begin{array}{c}\text { Bulk density } \\
\left(\mathrm{kg} \cdot \mathrm{m}^{-3}\right)\end{array}$ & $\begin{array}{c}\text { Porosity } \\
(\%)\end{array}$ \\
\hline R28 & 2306 & 1984 & 14.0 \\
R90 & 2320 & 1998 & 13.9 \\
EPP28 & 1798 & 1437 & 20.1 \\
EPP90 & 1800 & 1443 & 19.8 \\
\hline
\end{tabular}

The bulk density of concretes with incorporated EPP aggregates reached value of approx. $1440 \mathrm{~kg} \cdot \mathrm{m}^{-3}$. In this respect, these composites can be therefore classified as lightweight concretes (bulk density $<2000 \mathrm{~kg} \cdot \mathrm{m}^{-3}$ ) in D1.6 class in compliance with the standard EN 206-1 (2014) [36]. As we expected, the bulk and matrix densities of 90 days water curing samples were slightly greater than densities of specimens after 28 days of water curing. Both matrix and bulk density values obtained for EPP samples were lower than those measured for reference samples. This finding corresponds e.g. with $\mathrm{Gu}$ and Ozbakkaloglu [7] who reported in their review that the density of concretes containing plastic aggregates decreases with increasing substitution rate. This result has been observed irrespective of the type or size of used plastic aggregates, because generally plastic aggregates are lighter than natural aggregates. Porosity of both EPP and reference samples decreased with age of the materials. In accordance with the literature [15], the use of plastic aggregate resulted in the increased porosity compared to the reference mixture due to the addition of materials with an extremely heterogeneous morphology, which modified workability and amount of entrained air in the mixture.

Data on the mechanical parameters of tested concretes are given in Table 5.

Table 5. Mechanical properties of tested materials.

\begin{tabular}{lccc}
\hline Material & $\begin{array}{c}\text { Compressive } \\
\text { strength } \\
(\mathrm{MPa})\end{array}$ & $\begin{array}{c}\text { Flexural } \\
\text { strength } \\
(\mathrm{MPa})\end{array}$ & $\begin{array}{c}\text { Young's } \\
\text { modulus } \\
(\mathrm{GPa})\end{array}$ \\
\hline R28 & 53.6 & 9.7 & 25.7 \\
R90 & 54.3 & 10.7 & 25.8 \\
EPP28 & 20.8 & 5.1 & 8.1 \\
EPP90 & 21.4 & 5.9 & 10.9 \\
\hline
\end{tabular}

We can see that incorporation of EPP particles into the concrete mixture led to the decrease in all their mechanical parameters. Babu and Babu [16] stated that the strength of concrete is mainly influenced by the strength of used aggregate. This finding together with the higher porosity and the low bond strength between the surface of EPP particles and the cement paste resulting from the hydrophobic nature of EPP aggregates led to the decrease in mechanical parameters of the developed EPP lightweight concrete in comparison with reference concrete. In addition, plastic particles restricting water movement and thus can inhibit cement hydration reaction [14]. Obtained results are consistent with results of other papers, where plastics were used as aggregate for production of concretes/mortars as were reported e.g. by $[7,12,13,14,37]$. All mechanical characteristics of both reference and EPP samples increased with curing time due to the prolonged hydration time and development of denser concrete structure.

$\mathrm{Gu}$ and Ozbakkaloglu [7] stated that modulus of elasticity of concrete with incorporated plastic aggregates depends on a large number of parameters such as w/c, the type of waste plastic particles, the porosity of plastic particles, the replacement level etc. As it is the case for the compressive strength, Young's modulus of plastic waste concrete is generally lower than that of conventional concrete with the same w/c. This observation is in accordance with our results. Similarly, Tang et al. [38] reported the decrease in modulus of elasticity from $34.2 \mathrm{GPa}$ (reference concrete) to $14.5 \mathrm{GPa}$ (concrete with replacement of $60 \%$ by volume of natural aggregates by expanded polystyrene coarse aggregate). In general, incorporation of plastic aggregate led to the increased elastic incompatibility between the inclusion and the matrix.

Thermal parameters of developed concretes measured for dried samples are presented in Table 6 .

Table 6. Thermal parameters of tested materials (dry state).

\begin{tabular}{lccc}
\hline Material & $\begin{array}{c}\lambda \\
\left(\mathrm{W} \cdot \mathrm{m}^{-1} \cdot \mathrm{K}^{-1}\right)\end{array}$ & $\begin{array}{c}C_{v} \\
\left(\times 10^{6} \mathrm{~J} \cdot \mathrm{m}^{-3} \cdot \mathrm{K}^{-1}\right)\end{array}$ & $\begin{array}{c}a \\
\left(\times 10^{-6} \mathrm{~m}^{2} \cdot \mathrm{s}^{-1}\right)\end{array}$ \\
\hline R28 & 1.86 & 1.81 & 1.09 \\
R90 & 1.88 & 1.82 & 1.10 \\
EPP28 & 0.69 & 1.58 & 0.47 \\
EPP90 & 0.71 & 1.66 & 0.50 \\
\hline
\end{tabular}

The thermal conductivity of concrete depends mainly on its density and water content (thermal conductivity of water is 25 times greater than of air), but it is also affected by other factors such as the pore size distribution, chemical composition, crystallinity of the solid components and temperature. The thermal conductivity of a solid material tends to increase as its density, water content, temperature and percentage of crystalline phase increase. However, the thermal conductivity is only slightly affected by temperature for common temperature changes. The thermal parameters of concrete depend on the thermal characteristics of its phases, in particular the paste and aggregates. Therefore, as aggregates usually constitute about $70-80 \%$ of the concrete's volume, the incorporation of aggregates with low thermal conductivity might contribute to a significant increase in the thermal insulation capability of concrete $[39,40]$. The content of EPP particles with advantageous thermal parameters led to the substantial decrease in the thermal conductivity of the developed lightweight concrete. With $60 \%$ volume replacement of natural 
aggregate by EPP aggregate, there was a reduction in the thermal conductivity of $63 \%$ in comparison with the reference concrete sample. This result clearly reveals the positive effect of EPP aggregate incorporation on the thermal insulation properties of developed lightweight concrete. Samples with 90 days of water curing exhibited slightly higher thermal conductivity than 28-days samples; this is related to the fact that the older samples had a slightly lower porosity. Wang et al. [41] reported that the thermal conductivity of mortar with high impact polystyrene (HIPS) decreases to $87 \%, 69 \%$, and $44 \%$ that of regular mortar when the HIPS ratio is $10 \%, 20 \%$, and $50 \%$ by volume, respectively. Iucolano et al. [10] stated that partial replacement of silica sand with mix of plastic aggregates $(\mathrm{PP}+\mathrm{PE}+\mathrm{PET})$ in the amount of $20 \%$ in mass leads to reduction in the thermal conductivity of $50 \%$, passing from $0.38 \mathrm{~W} \cdot \mathrm{m}^{-1} \cdot K^{-1}$ of reference sample to $0.19 \mathrm{~W} \cdot \mathrm{m}^{-1} \cdot K^{-1}$ of mortar with incorporated plastic particles.

Significant influence of moisture content on the thermal conductivity of the examined concretes can be seen in Figure 11. Samples were measured from the dry state to fully water saturated state. Here, $100 \%$ of moisture content corresponds to the saturated moisture content expressed by mass. Basically, saturated moisture content matched the total open porosity of tested materials.

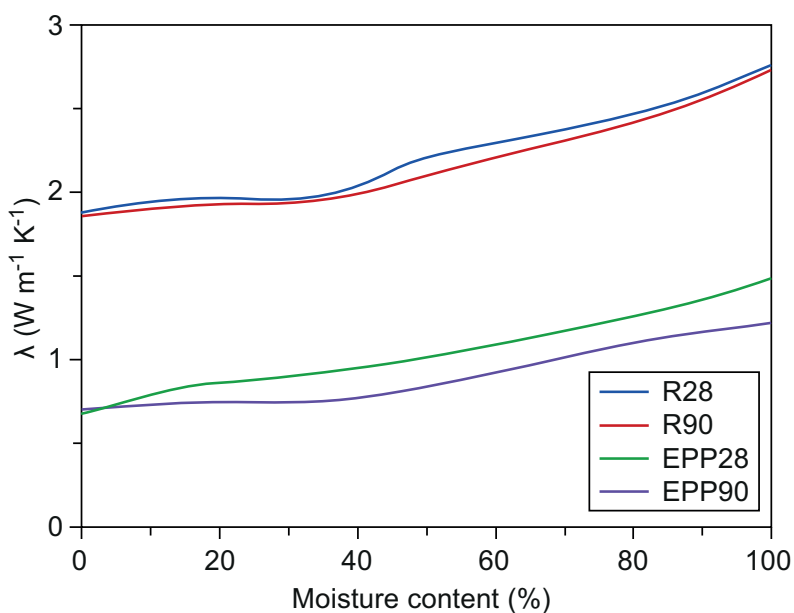

Figure 11. Thermal conductivity of tested material in dependence on moisture content.

As expected, with increase in moisture content the thermal conductivity increased for all analysed samples. The addition of EPP particles is resulting in a reduction of thermal conductivity even in presence of moisture, since EPP aggregates were inert for water penetration and their encapsulated porosity contributed to the improvement of thermal conductivity without negative moisture effect. For both 90-days samples were values of the thermal conductivity with presence of moisture lower compared to 28-days cured samples because of their lower porosity.
Liquid water transport properties of the developed materials are presented in Table 7.

Table 7. Water transport properties.

\begin{tabular}{lccc}
\hline Material & $\begin{array}{c}A \\
\left(\mathrm{~kg} \cdot \mathrm{m}^{-2} \cdot \mathrm{s}^{-1 / 2}\right)\end{array}$ & $\begin{array}{c}\kappa \\
\left(\mathrm{m}^{2} \cdot \mathrm{s}^{-1}\right)\end{array}$ & $\begin{array}{c}S \\
\left(\mathrm{~m}^{-2} \cdot \mathrm{s}^{-1 / 2}\right)\end{array}$ \\
\hline R28 & 0.0347 & $4.82 \mathrm{E}-8$ & $3.48 \mathrm{E}-5$ \\
R90 & 0.0337 & $4.74 \mathrm{E}-8$ & $3.38 \mathrm{E}-5$ \\
EPP28 & 0.0356 & $3.13 \mathrm{E}-8$ & $3.57 \mathrm{E}-5$ \\
EPP90 & 0.0345 & $3.09 \mathrm{E}-8$ & $3.46 \mathrm{E}-5$ \\
\hline
\end{tabular}

We can see that water absorption coefficient $A$ is for concrete with plastic aggregates only slightly higher than for reference material. This is probably related with higher total open porosity of developed lightweight concrete with EPP, where, however, plastic surface is inert for water penetration. These facts act in the opposite direction. Similar results, where water absorption increase with increasing content of plastic aggregates, were reported e.g. by da Silva [42].

The water vapour transmission properties of analysed concretes are summarized in Table 8. In results of water vapour transport parameters we observed greater differences between reference and EPP concrete samples than in the case of liquid water transport. For lightweight concrete with plastic aggregate we observed distinct increase in the water vapour transmission rate and thus decrease in the water vapour resistance factor $\mu$ compared to the reference material. The higher water vapour permeability of lightweight concrete we assign to its higher porosity and lower density compared to reference concrete. In accordance with the measuring principles of the used testing methods [43], for the wet-cup experimental arrangement we achieved lower $\mu$-values than for dry-cup testing procedure.

Table 8. Water vapour transport parameters determined by drycup and wet-cup method.

\begin{tabular}{lccccc}
\hline \multirow{2}{*}{ Material } & \multicolumn{2}{c}{ Dry-cup } & & \multicolumn{2}{c}{ Wet-cup } \\
\cline { 2 - 3 } \cline { 5 - 6 } & $\begin{array}{c}D \\
\left(\mathrm{~m}^{2} \cdot \mathrm{s}^{-1}\right)\end{array}$ & $\begin{array}{c}\mu \\
(-)\end{array}$ & & $\begin{array}{c}D \\
\left(\mathrm{~m}^{2} \cdot \mathrm{s}^{-1}\right)\end{array}$ & $\begin{array}{c}\mu \\
(-)\end{array}$ \\
\hline R28 & $6.29 \mathrm{E}-7$ & 39.4 & & $9.12 \mathrm{E}-7$ & 27.2 \\
R90 & $5.91 \mathrm{E}-7$ & 41.9 & & $8.41 \mathrm{E}-7$ & 29.5 \\
EPP28 & $1.24 \mathrm{E}-6$ & 20.0 & & $1.79 \mathrm{E}-6$ & 13.8 \\
EPP90 & $1.15 \mathrm{E}-6$ & 21.5 & & $1.55 \mathrm{E}-6$ & 16.0 \\
\hline
\end{tabular}

The sorption isotherms of tested materials are presented in Figure 12. As the relative humidity increases, the moisture content of all tested materials increases, due to adsorption of more water vapour. Generally, EPP concrete samples exhibit higher sorption capacity in comparison with reference samples. The Figure 12 shows different curves shapes for reference and for EPP concrete. The sorption isotherms measured for reference concrete exhibit for both curing periods in 
entire moisture range a similar pattern. On the other hand, for relative humidity $>50 \%$, the accumulated moisture content of EPP28 is higher than the one of EPP90.

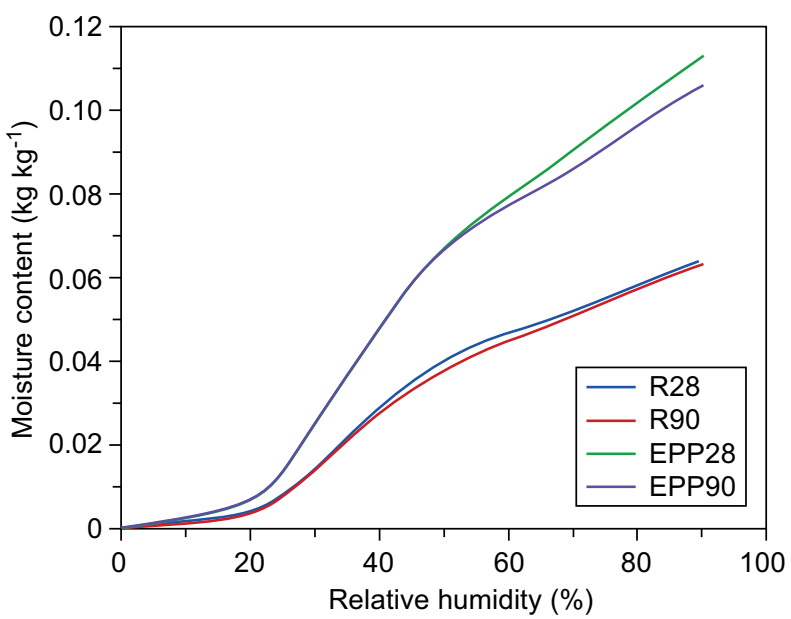

Figure 12. Sorption isotherms of tested materials.

\section{CONCLUSIONS}

This paper has reported the results of an experimental assessment of the properties of lightweight concrete prepared with expanded polypropylene waste aggregate. EPP allows create similar lightweight concrete as EPS. Generally, when selecting waste plastics for the production of lightweight concrete, it decides, among other things, the required final density, mechanical resistance and thermal properties. Compared to HDPE and fibre reinforced PP, EPP aggregate led to the significantly higher strength due to its better embedding in cement matrix. Based on the obtained results and discussion presented in this study, the following conclusions can be drawn:

- The workability of fresh concrete mixture with EPP aggregates in terms of the flow measurement decreased only about $6.7 \%$ compared to the reference mixture as the problems associated with the segregation and poor distribution of EPP particles in the mixture were totally solved by silica VP4 addition.

- The use of EPP aggregate in concrete composition resulted in decrease of both matrix and bulk densities of hardened concrete and increase of its porosity. Based on the bulk density value, the developed concrete with incorporated EPP particles can be classified as lightweight concrete.

- All the mechanical characteristics of lightweight concrete made with EPP decreased; 90 days compressive strength exhibit reduction to about $39 \%$, flexural strength to $55 \%$ and modulus of elasticity to $42 \%$ respectively, compared to reference material. However, the mechanical resistance of lightweight concrete is quite sufficient for intended use in non-structural applications for building subsoil or multi-layered floor structure and as the core of sandwich panels for prefabricated enclosures.

- EPP particles have significantly lower heat transport parameters than silica sand. Incorporation of EPP aggregates into cement-based matrix led to a great reduction in the thermal conductivity, even in the presence of moisture, which distinctly improves the thermal insulation properties of the examined lightweight concrete.

- The hygric parameters of the developed material with plastic aggregate are closely related with its porosity as well as with plastic impermeability for water. Therefore, the water absorption coefficient increased only slightly compared to the reference material. In terms of the water vapour transport parameters, the water vapour resistance factor $\mu$ of EPP concrete decreased to $51 \%$ of its value for concrete without EPP for dry-cup measurement and to $54 \%$ for wet-cup test arrangement. From the point of view of water vapour sorption capacity, EPP concrete samples exhibited higher sorption capacity in comparison with reference samples.

Summarizing the main findings of the presented work, one can conclude the recycling of waste plastics in the construction industry is promising solution to reduce the environmental impact in terms of natural resources and energy consumption, pollution and waste disposal. Moreover, the developed lightweight concrete is suitable material for the improvement of buildings thermal stability.

\section{Acknowledgment}

This research was financially supported by the Czech Science Foundation, under project No 17-04215S.

\section{REFERENCES}

1. Ozbakkaloglu T., Gu L., Gholampour A. (2017): ShortTerm Mechanical Properties of Concrete Containing Recycled Polypropylene Coarse Aggregates under Ambient and Elevated Temperature. Journal of Materials in Civil Engineering, 29, 1-10. doi: 10.1061/(ASCE)MT.1943-5533. 0002046

2. PlasticsEurope, Plastics - the Facts 2016, www.plasticseurope.org, consulted January 2017.

3. Coppola B., Courard L., Michel F., Incarnato L., di Maio L. (2016): Investigation on the use of foamed plastic waste as natural aggregates replacement in lightweight mortar. Composites Part B, 99, 75-83. doi:10.1016/j.compositesb. 2016.05.058

4. Dissanayake D.M.K.W., Jayasinghe C., Jayasinghe M.T.R. (2017): A comparative embodied energy analysis of a house 
with recycledexpanded polystyrene (EPS) based foam concrete wall panels. Energy and Buildings, 135, 85-94. doi:10.1016/j.enbuild.2016.11.044

5. Elzafraney M., Soroushian P., Deru M. (2005). Development of energy-efficient concrete buildings using recycled plastic aggregates. Journal of Architectural Engineering, 11, 122130. doi:10.1061/(ASCE)1076-0431(2005)11:4(122)

6. Záleská M., Pavlíková M., Pavlík Z. (2016): Properties of lightweight cement-based composites containing waste polypropylene. AIP Conference Proceedings, 1752, 040030. doi: 10.1063/1.4955261.

7. Gu L. and Ozbakkaloglu T. (2016): Use of recycled plastics in concrete: A critical review. Waste Management, 51, 1942. doi:10.1016/j.wasman.2016.03.005

8. Soloaga I.S., Oshiro A., Positieri M. (2014): The use of recycled plastic in concrete. An alternative to reduce the ecological footprint. Revista de la Construcción, 13, 19-26. doi: 10.4067/S0718-915X2014000300003

9. Yang S., Yue, X., Liu X., Tong Y. (2015): Properties of self-compacting lightweight concrete containing recycled plastic particles. Construction and Buildings Materials 84, 444-453. doi:10.1016/j.conbuildmat.2015.03.038

10. Iucolano F., Liguori B., Caputo D., Cioffi R. (2013): Recycled plastic aggregate in mortars composition: Effect on physical and mechanical properties. Materials and Design, 52, 916-922. doi:10.1016/j.matdes.2013.06.025

11. Corinaldesi V., Donnini J., Nardinocchi A. (2015): Lightweight plasters containing plastic waste for suitable and energy-efficient building. Construction and Buildings Materials, 94, 337-345. doi:10.1016/j.conbuildmat.2015. 07.069

12. Ruiz-Herrero J.L., Nieto D.V., López-Gil A., Arranz A., Fernández A., Lorenzana A., Merino S., De Saja J.A., Rodríguez-Pérez M.A. (2016): Mechanical and thermal performance of concrete and mortar cellular materials containing plastic waste. Construction and Building Materials, 104, 298-310. doi:10.1016/j.conbuildmat.2015. 12.005

13. Sharma R., Bansal P.P. (2016): Use of different forms of waste plastic in concrete e a review. Journal of Cleaner Production, 112, 473-482. doi:10.1016/j.jclepro. 2015.08.042

14. Saikia N., de Brito J. (2012): Use of plastic waste as aggregate in cement mortar and concrete preparation: A review. Construction and Building Materials, 34, 385-401. doi:10.1016/j.conbuildmat.2012.02.066

15. Colangelo F., Cioffi R., Liguori B. and Iucolano F. (2016): Recycled polyolefins waste as aggregates for lightweight concrete. Composites Part B, 106, 234-241. doi:10.1016/j. compositesb.2016.09.041

16. Babu K.G. and Babu D.S. (2003): Behaviour of lightweight expanded polystyrene concrete containing silica fume. Cement and Concrete Research, 33, 755-762. doi:10.1016/ S0008-8846(02)01055-4

17. Nurhayat D.F. (2018): Freeze-Thaw and Fire Resistance of Geopolymer Mortar Based in Natural and Waste Pozzolans. Ceramics-Silikáty, 62, 41-49. doi:10.13168/cs.2017.0043

18. Yun D., Lei W., Huaquan Y., Meijuan, R. (2017): Effects of Mineral Admixture on the Carbonic and Leaching Resistance of Cement-Based Materials. Ceramics-Silikáty, 61, 276-284. doi:10.13168/cs.2017.0026

19. Nurhayat D.F. (2017): Effect of Sodium Hydroxide Ratios on Durability of Geopolymer Mortars Containing Natural and Artificial Pozzolans. Ceramics-Silikáty, 61, 340-350. doi:10.13168/cs.2017.0033

20. Záleská M., Pokorný J., Pavlíková M., Pavlík Z. (2017): The thermal and mechanical performance of cement-based composites with enhanced thermal insulation properties. AIP Conference Proceedings, 1866, 040043. doi: 10.1063/ 1.4994523

21. EN 196-6 (1989): Methods of testing cement; Determination of fineness, CEN.

22. Záleská M., Pavlíková M., Pavlík Z., Jankovský O., Pokorný J., Tydlitát V., Svora P., Černý R. (2018): Physical and chemical characterization of technogenic pozzolans for the application in blended cements, Construction and Building Materials, 2018, 160, 106-116. doi:10.1016/j. conbuildmat.2017.11.021

23. Kaminskas R., Cesnauskas V. (2014): Influence of Activated Biomass Fly Ash on Portland Cement Hydration. Ceramics-Silikáty, 58, 260-268.

24. NF P 18-513 (2009): Pozzolanic Addition for Concrete Metakaolin - Definitions, Specifications and Conformity Criteria, AFN.

25. Záleská M., Pavlíková M., Pavlík Z. (2015): Classification of a-SiO $\mathrm{S}_{2}$ Rich Materials. Materials Science Forum, 824, 33-38. doi:10.4028/www.scientific.net/MSF.824.33

26. Fořt J., Pavlíková M., Záleská M., Pavlík Z., Trník A., Jankovský O. (2016): Preparation of puzzolana active two component composite for latent heat storage. CeramicsSilikáty, 60, 291-298. doi:10.13168/cs.2016.0044

27. Jankovský O., Pavlíková M., Sedmidubský D., Bouša D., Lojka M., Pokorný J., M. Záleská M., Pavlík Z. (2017): Study on pozzolana activity of wheat straw ash as potential admixture for blended cements, Ceramics-Silikáty, 61, 327339. doi:10.13168/cs.2017.0032

28. EN 12350-5 (2009): Testing fresh concrete - Part 5: Flow table test, CEN.

29. EN 12390-7 (2009): Testing hardened concrete - Part 7: Density of hardened concrete, CEN.

30. EN 196-1 (2016): Methods of testing cement - Part 1: Determination of strength, CEN.

31. Pavlík Z., Fořt J., Záleská M., Pavlíková M., Trník A., Medved I., Keppert M., Koutsoukos P.G., Černý R. (2016): Energy-efficient thermal treatment of sewage sludge for its application in blended cements. Journal of Cleaner Production, 112, 409-419. doi:10.1016/j.jclepro.2015.09. 072

32. Kumaran, M.K. (1999): Moisture diffusivity of building materials from water absorption measurements, Journal of Thermal Envelope and Building Science, 22, 349-355.

33. EN ISO 12572 (2001): Hygrothermal performance of building materials and products - Determination of water vapor transmission properties, CEN.

34. Pavlík, Z., Žumár, J., Medved', I., Černý, R. (2012): Water vapor adsorption in porous building materials: experimental measurement and theoretical analysis. Transport in Porous Media, 91, 939-954. doi:10.1007/s11242-011-9884-9

35. Záleská M., Pavlík Z., Pavlíková M., Scheinherrová L., J. Pokorný J., Trník A., Svora P, Fořt J., Jankovský O., Suchorab Z., Černý R. (2018): Biomass ash-based mineral admixture prepared from municipal sewage sludge and its application in cement composites. Clean Technologies and Environmental Policy, 20(1), 159-171. doi:10.1007/ s10098-017-1465-3 
36. EN 206-1 (2014): Concrete - Part 1: Specification, performance, production and conformity, CEN.

37. Alqahtani F.K., Ghataora G., Khan M.I. and Dirar S. (2017): Novel lightweight concrete containing manufactured plastic aggregate. Construction and Building Materials, 148, 386-397. doi:10.1016/j.conbuildmat.2017.05.011

38. Tang W., Lo Y., Nadeem A. (2008): Mechanical and drying shrinkage properties of structural-graded polystyrene aggregate concrete. Cement and Concrete Composites, 30, 403-409. doi:10.1016/j.cemconcomp.2008.01.002

39. Real S., Gomes M.G., Bogas J.A., Ferrer B. (2016): Thermal conductivity of structural lightweight aggregate concrete. Magazine of Concrete Research, 68, 798-808. doi:10.1680/jmacr.15.00424

40. Sayadi A.A., Tapia J.V., Neitzert T.R., Clifton G.Ch. (2016): Effects of expanded polystyrene (EPS) particles on fire resistance, thermal conductivity and compressive strength of foamed concrete, Construction and Building Materials, 112, 716-724. doi:10.1016/j.conbuildmat.2016.02.218

41. Wang R., Meyer Ch. (2012): Performance of cement mortar made with recycled high impact polystyrene. Cement and Concrete Composites, 34, 975-981. doi:10.1016/j.cemconcomp.2012.06.014

42. da Silva A.M., de Brito J., Veiga R. (2014): Incorporation of fine plastic aggregates in rendering mortars, Construction and Building Materials, 71, 226-236. doi:10.1016/j. conbuildmat.2014.08.026

43. Roels S., Carmeliet J., Hens H., Adan O., Brocken H., Cerny R., Pavlik Z., Hall Ch., Kumaran K., Pel L., Plagge R. (2004): Interlaboratory comparison of hygric properties of porous building materials. Journal of Thermal Envelope and Building Science, 27, 307-325. doi: 10.1177/ 1097196304042119 